\title{
Diabetes, hyperinsulinaemia, and coronary risk factors in Bangladeshis in East London
}

\author{
P M MCKEIGUE, * M G MARMOT, * Y D SYNDERCOMBE COURT, $\dagger$ \\ D E COTTIER, * SURAIYA RAHMAN, * R A RIEMERSMA \\ From the ${ }^{\star D e p a r t m e n t}$ of Community Medicine, University College and Middlesex School of Medicine, the \\ †Department of Haematology, London Hospital Medical College, and the †Cardiovascular Research Unit, \\ George Square, Edinburgh
}

SUMMARY Immigrants from the Indian subcontinent (South Asians) in England and Wales have higher morbidity and mortality from coronary heart disease than the general population; this seems to apply to both Hindus and Muslims. Studies in north west London and Trinidad found that the increased risk of coronary heart disease in Indians was not explained by dietary fat intakes, smoking, blood pressure, or plasma lipids. In the present study the distribution of coronary risk factors was measured in an East London borough where the mortality and attack rate from coronary heart disease are higher in the Asian population, predominantly Muslims from Bangladesh, than in the rest of the population. In a sample of 253 men and women aged 35-69 from general practice, mean plasma cholesterol concentrations were lower in Bangladeshi than in European men and women. Mean systolic blood pressures were $10 \mathrm{~mm} \mathrm{Hg}$ lower in Bangladeshis. Plasma fibrinogen concentrations were similar in Bangladeshis and Europeans and factor VII coagulant activity was lower in Bangladeshi than in European men. In contrast with the findings in Hindus in north west London, smoking rates were high in Bangladeshi men and the ratio of polyunsaturated fatty acids to saturated fatty acids in plasma lipids was lower in Bangladeshis than in Europeans. Diabetes was three times more common in Bangladeshis than in Europeans and serum insulin concentrations measured after a glucose load were twice as high in Bangladeshis. High insulin concentrations in Bangladeshis were associated with high plasma triglyceride and low high-density lipoprotein cholesterol concentrations.

Insulin resistance, leading to diabetes, hyperinsulinaemia, and secondary lipoprotein disturbances, is a possible mechanism for the high rates of coronary heart disease in South Asians in Britain and overseas.

Death rates from coronary heart disease in men and women born in the Indian subcontinent (South Asians) who live in England and Wales are higher than in the general population, and this high rate is shared by Gujaratis, Punjabis, South Indians, and Muslims. ${ }^{12}$ Similar findings have been reported for other Indian populations overseas. ${ }^{3}$ In a survey in the north west London boroughs of Brent and Harrow we found that South Asians had lower dietary intakes of saturated fat and cholesterol, higher ratios of dietary polyunsaturated to saturated fat, lower con-

Requests for reprints to Dr P M McKeigue, Department of Community Medicine, University College and Middlesex School of Medicine, 66-72 Gower Street, London WC1E 6EA.

Accepted for publication $16 \mathrm{June} 1988$ centrations of plasma cholesterol, and smoked less than the average for the British population." These findings were confirmed in Brent by other investigators 5 and yet the standardised mortality ratio for coronary heart disease for those born in the Indian subcontinent or East Africa who were resident in Brent or Harrow in 1979-83 was 163 for men and 157 for women.

This study of a Gujarati Hindu population provided no clues to the reasons for the increase in coronary heart disease, and the results did not accord with current thinking on the causes of coronary heart disease. This prompted us to study Muslims from the Sylhet region of Bangladesh who have settled in the East London borough of Tower Hamlets. In 1970-72 Bangladeshi men in this district were first reported to have a higher morbidity from coronary heart dis- 
ease. ${ }^{6}$ The objectives of our study were to determine whether the findings in north west London could be replicated in a Muslim population from the Indian subcontinent and secondly to investigate whether the increases in coronary heart disease in immigrants from the Indian subcontinent in Britain can be explained by other risk factors that were not measured in the earlier study, such as hypertension, increased haemostatic activity, and glucose intolerance.

\section{Methods}

\section{SAMPLING}

From published reports we estimated the size of difference in the distribution of each risk factor that would give rise to a $20 \%$ difference between two populations in coronary heart disease mortality in men. A target sample size sufficient to detect such differences was estimated to be about 80 men in each ethnic group. We obtained approval for the study from local ethics committees.

Fieldwork was undertaken between June 1985 and April 1986. The study area was defined as postal districts E1 and E2-the western half of the borough of Tower Hamlets. Most of the borough's Bangladeshi residents live in this area and are registered with one of three local practices. The lists of these three practices and of a further two practices with mostly native British patients were chosen as the sampling frame. A sample of men born between 1920 and 1949 was chosen from each practice, excluding residents in hostels for the single homeless and those with mental handicap, recent psychiatric illness, terminal malignancy, or other advanced disease. To minimise the proportion of wrong addresses, those who had not consulted their doctor since 1981 or who last attended for immunisation before returning to Bangladesh were also excluded because they were unlikely to be still resident. The proportions sampled from each practice were adjusted to ensure approximately equal numbers of Bangladeshi and control respondents. In three practices which had age-sex registers the sample was stratified by year of birth to give an even distribution across the age range. In the early stages of the study, women aged over 35 years who were married to Bangladeshi respondents were also invited to take part: because of the age difference between husbands and wives this proved to be an unsatisfactory means of sampling older Bangladeshi women. A sample of women was chosen independently from four of the practices in the last four months of fieldwork. In one practice whose list was made up predominantly of Bangladeshi residents, only women born before 1940 were included at this stage. Apart from the exclusions and the stratification by age, sex, and practice, the sampling procedure was random.

Each eligible person was sent a letter inviting them to participate. We visited addresses from which no reply was received to ascertain whether the address was correct and to issue a further invitation. Of the 557 people to whom letters were sent, 173 had moved to other addresses either outside the district or unknown, two had died, and one was in hospital. Of the 381 remaining, 58 refused, three were medically unfit to take part, and it was not possible to contact 12. Three hundred and eight interviews were completed-a response rate of $81 \%$ from those believed to be resident.

Respondents were interviewed at home with a questionnaire including demographic items, smoking, alcohol consumption, and medical history, and invited to attend the London Hospital Medical College for measurement of blood pressure and blood sampling. Most Bangladeshis were interviewed in Bengali (by SR) and most Europeans in English (by DEC or PMM). Those without a history of diabetes were asked to fast overnight and consume a $75 \mathrm{~g}$ glucose drink an hour and a half before their appointment. Two hundred and fifty three participants attended for examination, giving a final response rate of $66 \%$. The target sample size was reached for men but not for women. Table 1 shows the age distribution of the respondents. There were few Bangladeshi women who were younger than 45 or older than 54. This was a result of the unusual demographic structure of the population and the restriction of the Bangladeshi sample to women born before 1940 in the later stages of the fieldwork. Blood pressure was measured twice with a random zero sphygmomanometer after the subject had been sitting quietly for five minutes: all measurements were made by one observer (PMM). A single venous sample was obtained from 247 of the 253 attenders: in those who had been given a glucose load this was taken as close as possible to two hours after the reported time of consumption.

LABORATORY ANALYSES

Plasma treated with edetic acid was kept at $4^{\circ} \mathrm{C}$ for up to $\mathbf{4 8}$ hours before analysis. High density lipoprotein

Table 1 Numbers attending field station by age, sex, and ethric category

\begin{tabular}{|c|c|c|c|c|}
\hline \multirow{2}{*}{$\begin{array}{l}\text { Age } \\
\text { (yr) }\end{array}$} & \multicolumn{2}{|l|}{ Men } & \multicolumn{2}{|l|}{ Women } \\
\hline & Bangladeshi & Non-Asian & Bangladeshi & Non-Asian \\
\hline $\begin{array}{l}35-44 \\
45-54 \\
55-64 \\
65-69 \\
\text { All }\end{array}$ & $\begin{array}{r}17 \\
35 \\
22 \\
2 \\
76\end{array}$ & $\begin{array}{r}22 \\
35 \\
31 \\
2 \\
90\end{array}$ & $\begin{array}{r}3 \\
38 \\
4 \\
45\end{array}$ & $\begin{array}{r}12 \\
11 \\
18 \\
1 \\
42\end{array}$ \\
\hline
\end{tabular}


was separated by precipitation with heparin-manganese chloride; cholesterol in these specimens and in whole plasma was measured enzymatically in a centrifugal analyser. The concentration of plasma glucose was measured on a fluoride oxalate specimen by the glucose oxidase method. Fibrinogen concentrations in fresh citrated plasma were measured by a gravimetric method. ${ }^{7}$ Citrated plasma samples for factor VII determination were stored in liquid nitrogen, thawed at $37^{\circ} \mathrm{C}$, and maintained at room temperature to avoid cold activation. We assayed factor VII coagulant activity by a manual method based on that of Brozovic et al $^{8}$ with immuno AG $100 \%$ reference plasma in doubling dilutions from $1 /$ 10 to $1 / 360,0.025 \mathrm{~mol} / \mathrm{l}$ calcium chloride, and 1 in 32 rabbit brain thromboplastin. Factor VII deficient plasma was prepared from oxalated bovine blood by a modification ${ }^{8}$ of the method of Lechner and Deutsch. ${ }^{9}$ We measured the fatty acid composition of plasma lipids of a random subsample of those seen in the last six months of fieldwork by a technique described previously." Insulin concentrations in stored serum were measured by a double antibody technique. ${ }^{10}$

\section{STATISTICAL ANALYSES}

Mortality ratios for particular boroughs, expressed as percentages and determined for each sex separately, are based on population figures from the 1981 Census and on death records supplied by the Office of Population Censuses and Surveys. The standardised mortality ratio compares the observed number of deaths from coronary heart disease in Bangladeshis with the number that would be expected if the age specific mortality rates were the same in Bangladeshis as in all residents of the borough. The proportional mortality ratio compares the observed number of deaths from coronary heart disease in Bangladeshis with the number that would be expected if, in each age group, the proportion of deaths attributed to coronary heart disease were the same in Bangladeshis as in the general population of the borough. Unlike the standardised mortality ratio, the proportional mortality ratio does not depend on Census data and it measures the extent to which excess coronary mortality is cause specific.

All those of South Asian origin were included in the group referred to as Bangladeshi and all other subjects, including three Afro-Caribbeans, have been assigned to the non-Asian group: this is consistent with the grouping used in analyses of local morbidity and mortality. Participants were classified as diabetic if diabetes had been diagnosed or if their post-load plasma glucose was $\geqslant 11 \mathrm{mmol} / 1$. Known diabetic patients were excluded from the data for plasma insulin and triglycerides because they did not fast or receive a glucose load. To test for differences between ethnic groups we analysed data separately for men and women using a least squares linear model. Age was treated as a categoric variable with three levels corresponding to the age groups 35-44, 45-54, and 55-69 years. Adjusted means are the values predicted in the model when all covariates are held at their mean values. Other covariates-body mass index, triglycerides, and insulin-were treated as continuous variables. Triglyceride and insulin values were $\log$ transformed for these analyses but have been transformed back to SI units for the tabulations. In figs 1 and 2 data for women are given for only two age bands because of small numbers of Bangladeshi women at the extremes of the age range.

\section{Results}

\section{QUESTIONNAIRES}

Eighty nine per cent of Bangladeshi men and $80 \%$ of non-Asian men belonged to social classes III manual or IV by the Registrar General's classification. " Fifty three per cent of Bangladeshi men and $20 \%$ of nonAsian men were unemployed. Ninety seven per cent of Bangladeshis were Muslim and $91 \%$ were from Sylhet. Although most Bangladeshi men were

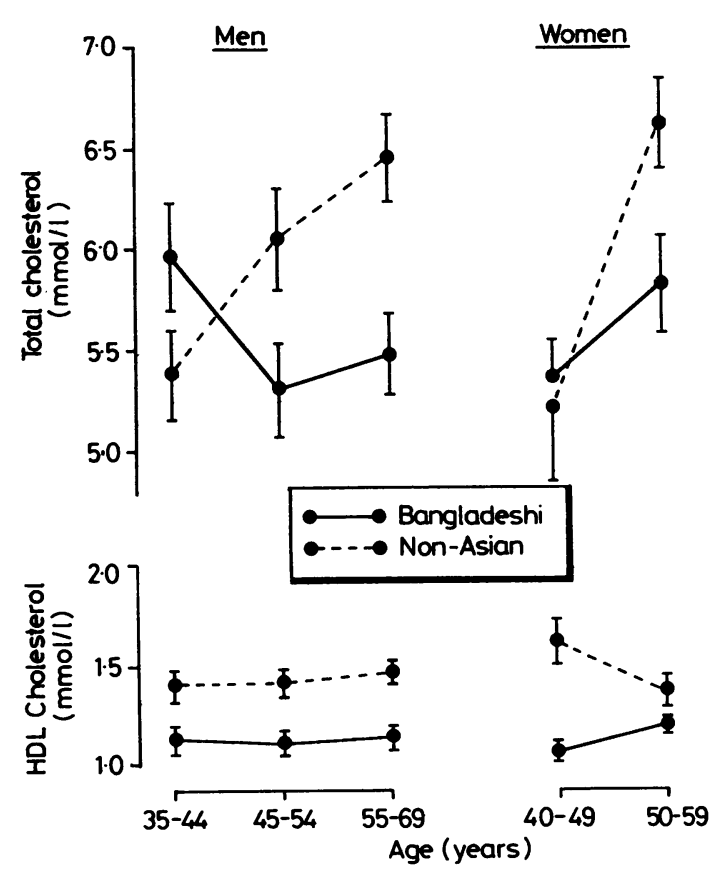

Fig 1 Concentrations of plasma total cholesterol and high density lipoprotein cholesterol by age, sex, and ethnic category. 

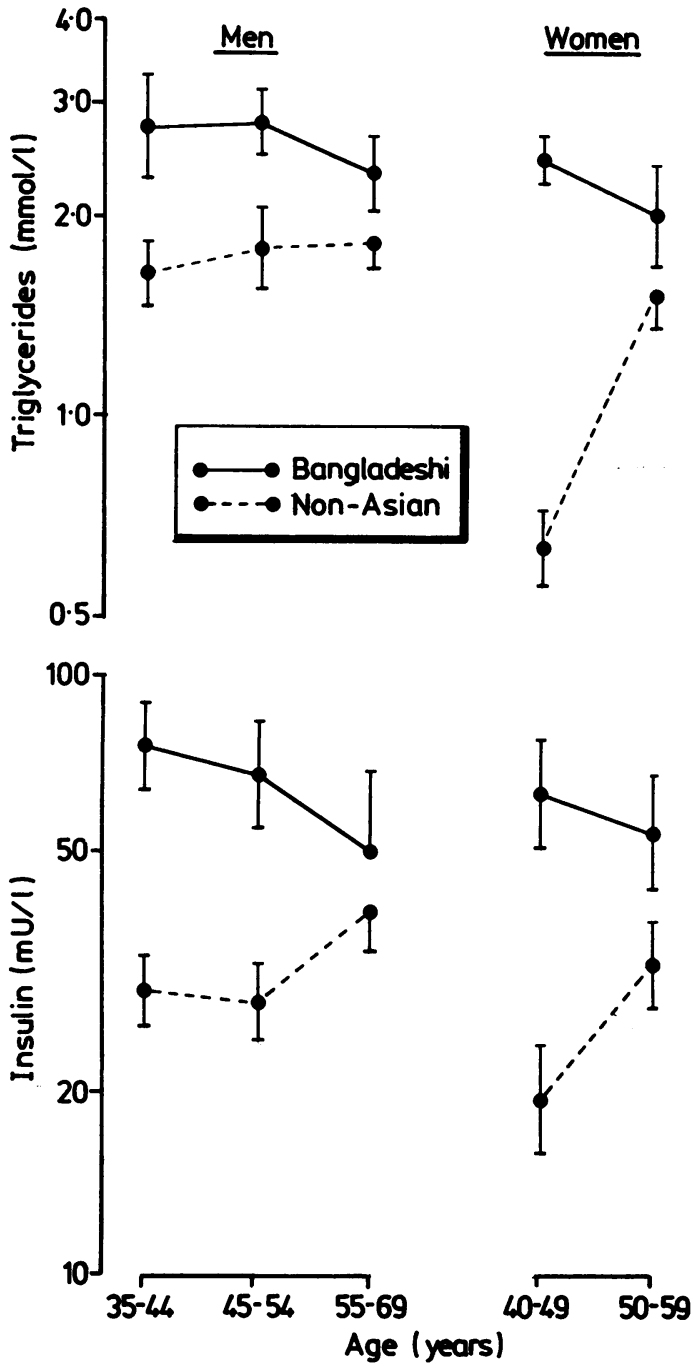

Fig 2 Concentrations of plasma triglycerides and serum insulin by age, sex, and ethnic category.

cigarette smokers, only $23 \%$ smoked > 15 cigarettes daily compared with $34 \%$ of non-Asian men. Ninety three per cent of Bangladeshi men and all Bangladeshi women were abstainers from alcohol.

\section{CLINICAL AND LABORATORY FINDINGS (TABLES 2 AND 3)}

Average systolic blood pressures were $10 \mathrm{~mm} \mathrm{Hg}$ lower in Bangladeshis than in non-Asians and about half of this difference disappeared after adjustment for body mass index. Concentrations of high density lipoprotein cholesterol were much lower and those of triglycerides much higher in Bangladeshis. The relation between age and systolic blood pressure, plasma cholesterol, plasma triglycerides, and serum insulin was less pronounced in Bangladeshis than in non-Asians (figs 1 and 2). The proportions of essential fatty acids of the $\omega 6$ series (predominantly linoleic acid) in plasma lipids and the polyunsaturated/saturated ratio were lower in Bangladeshis than in non-Asians (table 3). Concentrations of fatty acids of the $\omega 3$ series were slightly higher in the Bangladeshis: this is consistent with their high consumption of fish. Values for factor VII coagulant activity correlated with plasma cholesterol, but only part of the difference in factor VII activity between Bangladeshi and non-Asian men was explained by the difference in plasma cholesterol.

More than $20 \%$ of Bangladeshi men and women had diabetes. This was three times the rate in nonAsians (table 4). Two thirds of those with diabetes were already diagnosed: this proportion was similar in both groups. Serum concentrations of insulin after a glucose load were about twice as high in Bangladeshis as in non-Asians (fig 2). This difference persisted after controlling for the time of sampling. The insulin/glucose ratio was also higher in Bangladeshis. Insulin concentrations correlated with body mass index within each group. Insulin and triglyceride concentrations correlated with each other and inversely correlated with high density lipoprotein cholesterol: some of the difference in the concentrations of high density lipoprotein cholesterol between Bangladeshis and non-Asians was accounted for by the differences in plasma insulin and triglycerides.

\section{Discussion}

Although the surname analysis of deaths of Asians nationally ${ }^{2}$ and the $1970-72$ register $^{6}$ suggest that the high rates for coronary heart disease in immigrants from the Indian subcontinent in Britain are shared by the Bangladeshi population of Tower Hamlets, it is difficult to confirm this by analysis of local mortality data because the numbers of deaths are small. During 1979-83 there were 49 deaths from coronary heart disease among men born in Bangladesh aged 20-69 who were resident in Tower Hamlets; the standardised mortality ratio for coronary heart disease in Bangladeshi men was 118 (95\% confidence interval 85-151) and the proportional mortality ratio was 132 (95\% confidence interval 105-176). These estimates are consistent with the national data for coronary heart disease mortality in immigrants from the Indian subcontinent (South Asians). Bangladeshi women in Tower Hamlets are not yet old enough for 
Table 2 Risk factors (mean (SE), age adjusted for all variables except height) for coronary heart disease by sex and ethnic category

\begin{tabular}{|c|c|c|c|c|}
\hline \multirow[b]{2}{*}{ Risk factor } & \multicolumn{2}{|l|}{ Men } & \multicolumn{2}{|l|}{ Women } \\
\hline & Bangladeshi & Non-Asian & Bangladeshi & Non-Asian \\
\hline Current smokers (\%) & \multicolumn{2}{|c|}{$p<0.001$} & \multicolumn{2}{|l|}{ NS } \\
\hline Height (cm) & \multicolumn{2}{|c|}{$165(1) \quad p<0.001$} & \multicolumn{2}{|c|}{$p<0.001$} \\
\hline Body mass index $\left(\mathbf{k g} / \mathrm{m}^{2}\right)$ & \multicolumn{2}{|c|}{$p<0.001$} & \multicolumn{2}{|c|}{$p=0.06$} \\
\hline Systolic blood pressure (mm Hg) & $119(2) \quad p<$ & $129(2)$ & $113(3) \quad \mathrm{p}<$ & $123(3)$ \\
\hline Diastolic blood pressure (mm $\mathbf{H g})$ & $78(1)$ & $81(1)$ & $75(3)$ & $78(2)$ \\
\hline Plasma fibrinogen $(\mathbf{g} / \mathbf{l})$ & $\begin{array}{r}\text { NS } \\
3.03(0.11) \\
\text { NS }\end{array}$ & $3 \cdot 14(0 \cdot 10)$ & $\begin{array}{r}\text { NS } \\
3.04(0.12) \\
\text { NS }\end{array}$ & $3.17(0.09)$ \\
\hline Plasma factor VIIc ( $\%$ of reference value) & 90 (4) $\mathrm{p}<$ & $105(3)$ & $97(7)$ & $99(1)$ \\
\hline Plasma total cholesterol ( $\mathrm{mmol} / \mathrm{l})$ & $\begin{array}{r}5.53(0 \cdot 15) \\
p<\end{array}$ & $6.02(0 \cdot 13)$ & $5.37(0.25)$ & $5^{6.09(0.18)}$ \\
\hline & $\begin{array}{r}1 \cdot 13(0.04) \\
p<\end{array}$ & $01^{1.43(0.04)}$ & $1.19(0.08)$ & $1.45(0.05)$ \\
\hline Percentage of total cholesterol as HDL & $21 \cdot 3(1.0)$ & $25.3(0.9)$ & $22.4(1.5)$ & $25 \cdot 2(1 \cdot 0)$ \\
\hline Plasma triglycerides (mmol/l) & $2.59(0 \cdot 22)$ & $011.76(0 \cdot 13)$ & $1.77(0.26)$ & $1 \cdot 10(0 \cdot 11)$ \\
\hline Serum insulin ( $\mathrm{m} U / 1)$ & 65 (8) $p<$ & $0132(4)$ & 57 (13) $p<$ & $27(4)$ \\
\hline
\end{tabular}

HDL, high density lipoprotein.

deaths from coronary heart disease to be common in this group (two deaths observed during 1979-83, 1.8 expected).

This study confirms that the excess of coronary heart disease among South Asians in Britain is not explained by raised concentrations of plasma cholesterol. Though no direct dietary measurements were made in this study, the low plasma cholesterol and low polyunsaturated/saturated ratio in plasma lipids are consistent with lower intakes of total fat in Bangladeshis than non-Asians, if the Keys equation ${ }^{12}$ (a standard formula for predicting plasma cholesterol from dietary fat intake) holds. It is unlikely that the high dietary total fat intake and polyunsaturated/ saturated ratio reported in a study of 12 Bangladeshi men in this district are representative of the average diet of this population. ${ }^{13}$ The relatively high plasma cholesterol of Bangladeshi men aged under $\mathbf{4 5}$ years suggests that this group may be following a less traditional diet. The high proportion of smokers among Bangladeshi men differs from the low smoking rates of South Asian men recorded in north west London ${ }^{4}$ and in a nationally representative sample. ${ }^{14}$ The low concentrations of polyunsaturated fatty acids of the $\omega 6$ series in Bangladeshis contrast with the very high concentrations in Hindus in north west London. Although smoking and a low ratio of dietary polyunsaturated/saturated fat may contribute to the high rate for coronary heart disease of Bangladeshi men in East London, they cannot explain the national mortality pattern.

The high prevalence of diabetes, the hyperinsulin-

Table 3 Fatty acid composition of cholesterol esters by sex and ethnic category (mean (SE))

\begin{tabular}{|c|c|c|c|c|}
\hline & \multicolumn{2}{|l|}{ Men } & \multicolumn{2}{|l|}{ Women } \\
\hline & $\begin{array}{l}\text { Bangladeshi } \\
\text { (27) }\end{array}$ & $\begin{array}{l}\text { Non-Asian } \\
(44)\end{array}$ & $\begin{array}{l}\text { Bangladeshi } \\
\text { (37) }\end{array}$ & $\begin{array}{l}\text { Non-Asian } \\
\text { (38) }\end{array}$ \\
\hline Saturated (\%) & \multicolumn{2}{|c|}{$\begin{array}{rl}14.2(0.3) & p<0.001 \\
p & 12.8(0.2)\end{array}$} & \multicolumn{2}{|c|}{$\underbrace{14.2(0.2)}_{\mathrm{p}}<0.001^{12.3(0.2)}$} \\
\hline $\begin{array}{l}\text { Polyunsaturated: } \\
\text { W6 series (\%) } \\
\omega 3 \text { series (\%) } \\
\text { Ratio of polyunsaturated to saturated }\end{array}$ & $\begin{array}{c}56.6(1.4) \\
N S \\
2.78(0.22) \\
p= \\
4.28(0.18) \\
p<\end{array}$ & $\begin{array}{l}58 \cdot 3(1 \cdot 1) \\
2 \cdot 23(0 \cdot 17) \\
5.81(0 \cdot 14)\end{array}$ & \multicolumn{2}{|c|}{ 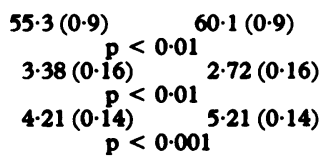 } \\
\hline
\end{tabular}


Table 4 Frequency of diabetes by age, sex, and ethnic category

\begin{tabular}{|c|c|c|c|c|}
\hline \multirow{2}{*}{$\begin{array}{l}\text { Age } \\
(y r)\end{array}$} & \multicolumn{2}{|l|}{ Men } & \multicolumn{2}{|l|}{ Women } \\
\hline & Bangladeshi & Non-Asian & Bangladeshi & Non-Asian \\
\hline $\begin{array}{l}35-44 \\
45-54 \\
55-64 \\
\text { All, age- }\end{array}$ & $\begin{array}{r}2 / 17 \\
10 / 32 \\
4 / 22\end{array}$ & $\begin{array}{l}1 / 22 \\
4 / 34 \\
3 / 28\end{array}$ & $\begin{array}{l}1 / 2 \\
9 / 36 \\
0 / 3\end{array}$ & $\begin{array}{l}0 / 12 \\
0 / 11 \\
3 / 18\end{array}$ \\
\hline adjusted & $22 \%$ & $10 \%$ & $23 \%$ & $4 \%$ \\
\hline
\end{tabular}

aemia after a glucose load, the high concentrations of plasma triglycerides, and low concentrations of high density lipoprotein cholesterol found in this South Asian population are all factors associated with increased risk of coronary heart disease in other populations: they appear to be part of a general pattern found in South Asians overseas and may represent different manifestations of a single metabolic disturbance. The $22 \%$ prevalence of diabetes in this small sample is similar to the figure reported for other populations of South Asians overseas $^{15-17}$ but much higher than the $1.3 \%$ in a comparable survey in East Pakistan in 1964. ${ }^{18}$ Plasma concentrations of insulin have been reported to be higher in Asians than Europeans in South Africa ${ }^{19}$ and in a hospital-based sample in West London. ${ }^{21}$ High concentrations of triglycerides and low concentrations of high density lipoprotein cholesterol in South Asians compared with Europeans have also been reported in Trinidad ${ }^{22}$ and the United States. ${ }^{23}$ In our small sample there was no sex difference in the concentrations of high density lipoprotein cholesterol in either the Bangladeshi or the other groups: while absence of sex difference has been reported in other South Asian populations ${ }^{425} 20$ the absence of the usual sex difference of about 0.3 $\mathrm{mmol} / \mathrm{l}$ in the European group is puzzling since the $95 \%$ confidence interval for the difference $(-0.15$ to $+0.15 \mathrm{mmol} / \mathrm{l})$ is less than the usual difference and it is therefore unlikely to be explained entirely by chance or random measurement error.

Associations between raised concentrations of plasma insulin, high concentrations of triglycerides, and low concentrations of high density lipoprotein cholesterol have been reported in other populations ${ }^{27-29}$ : hyperinsulinaemia increases the synthesis of very low density lipoprotein triglyceride synthesis ${ }^{27} 30$ and this may have a reciprocal effect on the concentration of high density lipoprotein cholesterol. ${ }^{31}$ Definitive demonstration of insulin resistance requires steady state measurements of glucose disposal and insulin concentrations, but the parallel findings of a raised insulin/glucose ratio and high frequency of diabetes in this South Asian population make it reasonable to infer that insulin resistance underlies the increased insulin concentrations.

The high insulin concentrations in Bangladeshis were not explained by high body mass index; however, this index may be inappropriate for comparing adiposity in groups with different mean frame sizes. ${ }^{32}$ In other populations insulin concentrations are more closely related to deposition of fat on the upper body, which was not measured in this study, than to body mass index..$^{33}$ Pathological and epidemiological evidence support the view that the combination of raised plasma insulin, raised triglycerides, and low concentrations of high density lipoprotein cholesterol is atherogenic. ${ }^{3-36}$

Our results and those of other investigators indicate that the evidence relating to high fat diet, plasma cholesterol, hypertension, and smoking to the occurrence of coronary heart disease does not account for the high rates of coronary heart disease rates in South Asians overseas ${ }^{515}$; any attempt at an explanation must therefore invoke less well established risk factors. On the basis of these findings we suggest a unitary hypothesis for the mechanism of high rates of coronary heart disease and diabetes in South Asians overseas: insulin resistance may be responsible for hyperinsulinaemia, secondary disturbances of lipoprotein metabolism, and a high prevalence of non-insulin-dependent diabetes. This metabolic pattern might lead to accelerated atherogenesis either through a direct effect of insulin upon the arterial wall or as a result of the changes in lipoprotein concentrations. We are now planning a larger study to test this hypothesis and to investigate the relation of these metabolic differences to adiposity, diet, physical activity, and social environment. If the hypothesis is correct then measures to reduce hyperinsulinaemia, such as weight reduction and increased exercise, may be the most effective means of preventing coronary heart disease in South Asians.

This study was supported by the British Heart Foundation. P M McK is a Wellcome Training Fellow in Clinical Epidemiology. We are grateful to the general practitioners who gave permission for their patients to be studied, to the East London Mosque Trust for their help with publicity, and to Karen Lyall and Wendy Middlemass for the fatty acid analyses.

\section{References}

1 Marmot MG, Adelstein AM, Bulusu L. Lessons from the study of immigrant mortality. Lancet 1984;i:1455-8.

2 Balarajan R, Adelstein AM, Bulusu L, Shukla V. Patterns of mortality among migrants to England and 
Wales from the Indian subcontinent. Br Med $J$ 1984;289:1185-7.

3 Anonymous. Coronary heart disease in Indians overseas. Lancet 1986;i:1307-8.

4 McKeigue PM, Marmot MG, Adelstein AM, et al. Diet and risk factors for coronary heart disease in Asians in north-west London. Lancet 1985;i1:1086-90.

5 Miller GJ, Kotecha S, Wilkinson WH, et al. Dietary and other characteristics relevant for coronary heart disease in men of Indian, West Indian and European descent in London. Atherosclerosis 1988;70:63-72.

6 Tunstall Pedoe H, Clayton D, Morris JN, Brigden W, McDonald L. Coronary heart attacks in East London. Lancet 1975;ii:833-8.

7 Fearnley GR, Chakrabarti R. Fibrinolytic treatment of rheumatoid arthritis with phenformin plus ethyloestrenol. Lancet 1966;i1:757-61.

8 Brozovic M, Stirling Y, Harricks C, North WRS, Meade TW. Factor VII in an industrial population. Br J Haematol 1974;28:381-91.

9 Lechner K, Deutsch E. Eine einfache Methode zur Herstellung von menschlichen Factor-VII-Mangelplasma. Thrombosis et Diathesis Haemorrhagica 1967;18:252-8.

10 Sonksen PH. Double antibody technique for the simultaneous assay of insulin and growth hormone. In: Antoniades HN, ed. Hormones in human blood. Detection and assay. Cambridge, Massachusetts: Harvard University Press, 1976:176-99.

11 Office of Population Censuses and Surveys. Classification of occupations. London: HMSO, 1980.

12 Keys A, Anderson JT, Grande F. Serum cholesterol responses to changes in the diet. III. Differences among individuals. Metabolism 1965;14:766-75.

13 Silman A, Loysen E, de Graef W, Sramek M. High dietary fat intake and cigarette smoking as risk factors for ischaemic heart disease in Bangladeshi male immigrants in East London. J Epidemiol Community Health 1985;39:301-3.

14 Balarajan R, Yuen P. British smoking and drinking habits: variation by country of birth. Community Med 1986;8:237-9.

15 Beckles GLA, Miller GJ, Kirkwood BR, Alexis SD, Carson DC, Byam NTA. High total and cardiovascular disease mortality in adults of Indian descent in Trinidad, unexplained by major coronary risk factors. Lancet 1986; i:1298-301.

16 Zimmet P, Taylor R, Ram P, et al. Prevalence of diabetes and impaired glucose tolerance in the biracial (Melanesian and Indian) population of Fiji: a ruralurban comparison. Am J Epidemiol 1983;118:673-88.

17 Omar MAK, Seedat MA, Dyer RB, Rajput MC, Motala AA, Joubert SM. The prevalence of diabetes mellitus in a large group of South African Indians. $S$ Afr Med J 1985;67:924-6.

18 West KM, Kalbfleisch JM. Glucose tolerance, nutrition and diabetes in Uruguay, Venezuela, Malaya and East Pakistan. Diabetes 1966;15:9-18.

19 Keller P, Schatz L, Jackson WPU. Immunoreactive insulin in various South African population groups. $S$
Afr Med J 1972;46:152-7.

20 Notelovitz M. An interracial comparison of insulin secretion in normal non-pregnant women. S Afr Med J 1976;50:1214-7.

21 Mohan V, Sharp PS, Cloke HR, Burrin JM, Schumer B, Kohner EM. Serum immunoreactive insulin responses to a glucose load in Asian Indian and European Type 2 (non-insulin-dependent) diabetic patients and control subjects. Diabetologia 1986;29:235-7.

22 Miller GJ, Beckles GLA, Alexis SD, Byam NT, Price SGL. Serum lipoproteins and susceptibility of men of Indian descent to coronary heart disease. The St James survey, Trinidad. Lancet 1982;i1:200-3.

23 Reddy MN, Krishnaiah KV, Sehadri B. Total cholesterol (TC), high density lipoprotein cholesterol (HDL) and its subfractions (HDL-2) and (HDL-3), and triglyceride (TG) levels in people of Asian Indian origin. Clin Chem 1984;30:991.

24 Thomas I, Gupta S, Sempos C, Cooper R. Serum lipids of Indian physicians living in the US compared to US-born physicians. Atherosclerosis 1986;61:99-106.

25 Gandhi BM. Lipoprotein composition of normal healthy subjects in northern India. Indian $J$ Med Res 1982;75:393-401.

26 Shanmugasundaram KR, Suresh S, Misra KP, Jayakrishan TK. Plasma lipoprotein cholesterol in India in healthy persons and those with coronary heart disease. Atherosclerosis 1983;46:129-35.

27 Olefsky JM, Farquhar JW, Reaven GM. Reappraisal of the role of insulin in hypertriglyceridemia. Am J Med 1974;57:551-60.

28 Stalder M, Pometta D, Suenram A. Relationship between high plasma insulin levels and high density lipoprotein cholesterol levels in healthy men. Diabetologia 1981;21:544-8.

29 Orchard TJ, Becker DJ, Bates M, Kuller LH, Drash AL. Plasma insulin and lipoprotein concentrations: an atherogenic association? Am J Epidemiol 1983;118:326-37.

30 Reaven GM, Lerner MP, Stern MP, Farquhar JW. Role of insulin in endogenous hypertriglyceridaemia. $J$ Clin Invest 1967;46:1756-67.

31 Schaeffer EJ, Levy RI, Anderson DW, Danner RN, Brewer HB, Blackwelder WC. Plasma triglycerides in regulation of HDL cholesterol levels. Lancet 1978; i1:391-2.

32 Grimley Evans J, Prior IAM. Indices of obesity derived from height and weight in two Polynesian populations. Br J Prev Soc Med 1969;23:56-9.

33 Krotkiewski M, Bjorntorp P, Sjostrom L, Smith U. Impact of obesity on metabolism in men and women: importance of regional adipose tissue distribution. $J$ Clin Invest 1983;72:1150-62.

34 Stout RW. Insulin and atheroma-an update. Lancet 1987;i:1077-8.

35 Riemersma RA. Coronary artery disease: raised cholesterol or triglycerides? Int J Cardiol 1984;5:193-4.

36 Miller GJ, Miller NE. Plasma high-density lipoprotein concentration and development of ischaemic heart disease. Lancet 1975;i:16-9. 